\title{
Argentina: Difusión del algodón GM e impacto en la rentabilidad de los pequeños productores de la Provincia del Chaco
}

\author{
Valeria Arza, Laura Goldberg y Claudia Vazquez
}

En este trabajo se analiza la adopción del algodón genéticamente modificado (GM) por parte de pequeños productores del Chaco, Argentina. Se utiliza el marco conceptual de la configuración socio-técnica de la tecnología, en que se postula que existe un conjunto de factores que inciden de manera relevante en la forma en que funcionan las tecnologías. Desde este marco, se describen las condiciones en que los pequeños productores del Chaco adoptan el algodón GM y se señalan las diferencias existentes con los grandes productores, en quienes se centra la mayor parte de la literatura. A partir de metodologías cualitativas, se analizan las rupturas y continuidades ocurridas desde la introducción del algodón GM en las prácticas productivas que afectan a la rentabilidad de los pequeños productores. Se constata que las dificultades productivas que estos enfrentan no han variado esencialmente $y$, en algunos casos, se han profundizado.

PALABRAS CLAVE

CLASIFICACIÓN JEL

AUTORES
Algodón, cultivos, organismos genéticamente modificados, pequeñas explotaciones agrícolas, productividad, ingresos, condiciones económicas, Argentina

O13, O33, Q16

Valeria Arza es investigadora del Consejo Nacional de Investigaciones Científicas y Técnicas (CoNicET) y del Centro de Investigaciones para la Transformación (cENIT).varza@fund-cenit.org.ar

Laura Goldberg es investigadora del Centro de Investigaciones para la Transformación (cENIT). lgoldberg@fund-cenit.org.ar

Claudia Vazquez es investigadora del Centro de Investigaciones para la Transformación (CEnit). claudiavazquez@fund-cenit.org.ar 


\section{I}

\section{Introducción}

Desde su lanzamiento en la Argentina en 1996, los cultivos genéticamente modificados (GM) se expandieron muy rápidamente con tasas de adopción que figuran entre las más elevadas del mundo. El algodón GM se introdujo en 1998 y ya en 2010 prácticamente toda la superficie sembrada con ese cultivo correspondía a variedades transgénicas. Si bien la rapidez de su difusión podría estar reflejando los beneficios que la tecnología GM representa para los usuarios, a lo largo de este trabajo se aprecia que estos beneficios no han sido iguales para todos: los transgénicos fueron más funcionales a las condiciones de producción de los grandes productores.

El mayor aporte del algodón GM a la rentabilidad se vincula al ahorro de costos de mano de obra y pesticidas. Sin embargo, los pequeños productores no aprovecharon dicho ahorro en la misma medida que los grandes porque no contratan mano de obra ni usan pesticidas en igual medida que aquellos. Además, la plaga principal que azota actualmente a la región —el picudo del algodonero- no está entre los insectos que controlan las semillas GM disponibles. Asimismo, como se argumentará en este trabajo, la introducción de los cultivos GM podría haber profundizado otros problemas socioproductivos de los pequeños productores, relacionados con su posición desventajosa en la cadena de comercialización.

De hecho, muchos pequeños productores han abandonado el cultivo del algodón en los últimos años y en algunos casos han llegado a vender sus tierras. Según la opinión de algunos técnicos y funcionarios provinciales, la producción de algodón ya no es viable para los pequeños productores en el Chaco. Aunque esta situación pudo haber comenzado antes de la introducción de la tecnología GM, ya que es congruente con la expansión del paradigma "productivista" que

\footnotetext{
$\square$ Este estudio se llevó a cabo con el apoyo financiero del Centro Internacional de Investigaciones para el Desarrollo (IDRC, por sus siglas en inglés), Ottawa, Canadá, y del Consejo Nacional de Investigaciones Científicas y Técnicas (CONICET), Proyecto PIP 112-200801-02758, Argentina. Las autoras agradecen a funcionarios de la Subsecretaría de Desarrollo Rural y Agricultura Familiar del Gobierno de la Provincia del Chaco, a investigadores y extensionistas del Instituto Nacional de Tecnología Agropecuaria (INTA) y representantes de los consorcios rurales de las localidades visitadas, por toda la ayuda brindada durante el trabajo de campo. También se agradecen los comentarios recibidos por un árbitro anónimo de la Revista CEPAL.
}

intenta generar y aprovechar las economías de escala (Vanloqueren y Baret, 2009) ${ }^{1}$, en este trabajo se sostiene que la adopción de dicha tecnología ha profundizado la brecha entre grandes y pequeños productores, contribuyendo a alimentar la percepción de que el algodón no es viable en pequeña escala.

En la mayoría de los trabajos en que se analiza la repercusión de los cultivos GM en la Argentina se estudia la tecnología como artefacto. Es decir, se pone el foco en las virtudes de las semillas GM y su paquete tecnológico asociado (Qaim y de Janvry, 2003 y 2005; Trigo y Cap, 2006; Trigo y otros, 2002; Trigo, FalckZepeda y Falconi, 2010), y se evalúa cuán efectivas son las semillas resistentes a insectos y tolerantes a herbicidas (cuánto pesticida o trabajo ahorran) y cuáles son los efectos económicos en términos de cambios en los rendimientos y la rentabilidad.

Dentro de este grupo, en la literatura específica sobre algodón GM en la Argentina se concluye que su adopción —en particular las semillas resistentes a insectos lepidópteros - ha aumentado los rendimientos de la producción de algodón debido al mejor manejo de plagas (Qaim y de Janvry, 2005; Trigo y Cap, 2006). Sin embargo, estos estudios no se centran en los pequeños productores, sino que se basan o bien en información proveniente de encuestas a productores relativamente grandes, o en ejercicios de modelización agregados para el conjunto de productores. Además, en la medida en que en estos trabajos se adjudican al artefacto todas las virtudes que puede producir la tecnología, no se analizan en profundidad las diferencias existentes en el contexto de adopción de diferentes usuarios. Por ejemplo, se asume que las semillas GM fueron en general adoptadas dentro de un paquete que incluye buenas prácticas agronómicas, insumos específicos y maquinaria moderna. Sin embargo, mientras que los grandes productores suelen acceder al paquete tecnológico completo, los productores más pequeños en general acceden a un paquete incompleto que consiste en semillas GM no certificadas y de baja calidad y herbicida utilizado de manera errática.

\footnotetext{
${ }^{1}$ El paradigma productivista es una parte relevante de la agenda nacional de agricultura en la Argentina desde la década de 1970 (véanse, por ejemplo, Becerra, Baldatti y Pedace, 1997; y Gárgano, 2011).
} 
En este trabajo se adopta una visión más amplia de las tecnologías, entendidas como "configuraciones socio-técnicas" en lugar de considerarlas artefactos individuales (semillas, máquinas, y otros). El concepto de configuración socio-técnica fue desarrollado en los campos de la sociología y la economía de la ciencia y la tecnología (Bijker, 1995; Klein y Kleinman, 2002; Kleinman, 1995; Pinch, 1996; Pinch y Bijker 1987; Rosen, 1993; Williams y Edge, 1996), desde donde se sostiene que las tecnologías deben ser entendidas en relación con los contextos en que son producidas, comercializadas y adoptadas.

Según este enfoque, el artefacto es solo uno de los aspectos que caracterizan a una configuración sociotécnica, la que también incluye los aspectos sociales, culturales, políticos y económicos. Respecto de ellos, en este trabajo el foco se pone en las capacidades y prácticas de los usuarios y su poder de negociación frente a otros actores relevantes en la cadena productiva. El enfoque socio-técnico propone que el "funcionamiento" del artefacto varía para diferentes configuraciones sociotécnicas. En tal sentido, este enfoque permite apreciar la flexibilidad de las tecnologías: cuando el contexto social cambia, las tecnologías tienen distintos efectos, consecuencias y significados.

En el presente estudio se muestra que la configuración socio-técnica del algodón GM es marcadamente diferente según se trate de pequeños o grandes productores. Por lo tanto, aunque en la literatura existente se concluye que la introducción de la tecnología GM aumentó inequívocamente la rentabilidad de la producción de algodón, en este trabajo se relativiza esa conclusión y se plantea que en la provincia del Chaco su adopción no tuvo los mismos efectos para todos los productores. El principal argumento del trabajo es que la tecnología GM, en el caso del algodón en la provincia del Chaco, ha tenido diferentes efectos económicos para los productores grandes y pequeños, y ha implicado un incremento de las desigualdades entre ellos.
La evidencia empírica que aquí se maneja proviene de talleres participativos con pequeños productores de algodón, realizados en julio y septiembre de 2010 y en julio de 2011 en cuatro localidades algodoneras de la provincia del Chaco (Pampa del Indio, Quitilipi, Villa Berthet y Sáenz Peña). En cada taller participaron alrededor de 20 personas, principalmente pequeños productores (que producían en menos de 10 hectáreas), pero también algunos productores medianos (que producían en menos de 100 hectáreas), intermediarios, extensionistas del Instituto Nacional de Tecnología Agropecuaria (INTA) y funcionarios locales. Los talleres se organizaron utilizando metodologías participativas destinadas a identificar las prácticas productivas, los problemas y las posibles soluciones, con una duración aproximada de un día y medio cada uno. La información recolectada durante los talleres se complementó con entrevistas en profundidad ${ }^{2}$ a agentes del INTA (8), representantes del gobierno (1), representantes de cooperativas de productores (2), productores líderes de organizaciones (2) y representantes de la industria de semillas (2).

El trabajo se organiza en tres secciones además de esta Introducción. En la sección II se presenta el contexto de adopción del algodón GM. Se describe la evolución histórica de la producción de algodón y se detallan las principales características de las prácticas productivas de los grandes y pequeños productores. En la sección III se analizan los cambios en las prácticas productivas con la difusión de las semillas GM, a partir de la información cualitativa recolectada en los talleres. En primer lugar se abordan los cambios en los rendimientos y luego aquellos relacionados con la rentabilidad. Finalmente, en la sección IV se entregan las conclusiones y se presentan lineamientos de política.

\footnotetext{
${ }^{2}$ Los números se refieren a las sesiones de entrevistas organizadas y no a las personas concretamente entrevistadas, ya que en varias sesiones se entrevistaron múltiples personas.
} 


\section{II}

\section{La producción de algodón en la Argentina y las prácticas de los pequeños productores del Chaco}

\section{Principales características de la producción de algodón}

En la provincia del Chaco se concentra cerca del $60 \%$ del área sembrada con algodón de la Argentina (véase el gráfico 1) ${ }^{3}$. Es una de las provincias más pobres del país: en 2009 el índice de desarrollo humano calculado por las Naciones Unidas ubicaba al Chaco como la tercera provincia más pobre de la Argentina. Según datos

${ }^{3}$ En promedio para los años 1969 a 2010, la producción de algodón del Chaco constituyó el $62 \%$ de la producción total del país (Ministerio de Agricultura, Argentina). del año 2002 (último Censo Nacional Agropecuario con información disponible), en la provincia existían 18.000 trabajadores de algodón, de los cuales 13.000 eran trabajadores familiares (Valenzuela y Scavo, 2009). Como se observa en el cuadro 1, una pequeña proporción de grandes productores era responsable de la mitad de la superficie sembrada con algodón, al tiempo que la mayoría de los productores $(60 \%)$ producía en parcelas de menos de 10 hectáreas. En la subsección número 2 se describen en detalle las principales prácticas de estos dos grupos.

La producción de algodón en el Chaco comenzó a principios del siglo XX y presentó grandes fluctuaciones

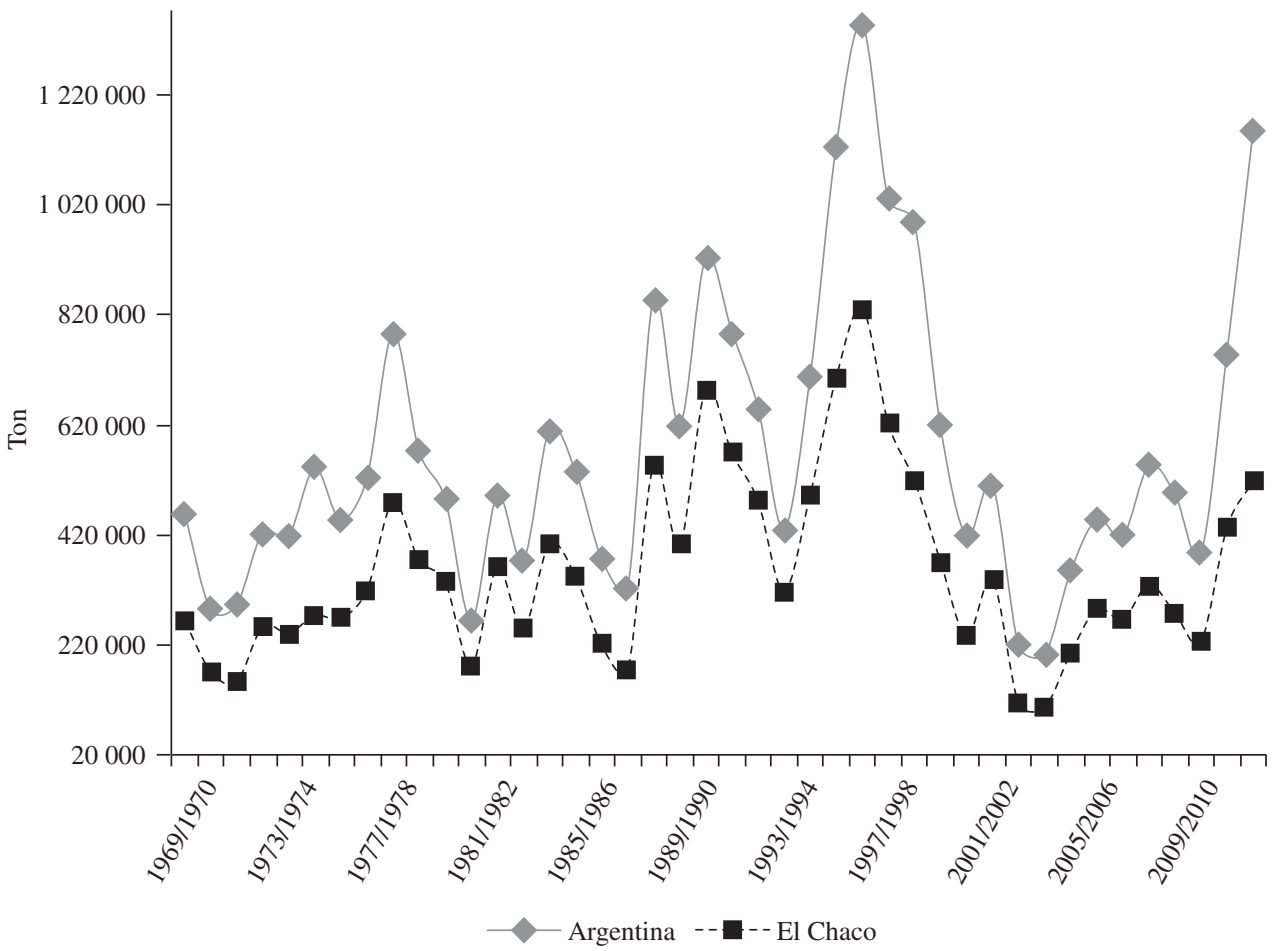

Fuente: elaboración propia sobre la base del Sistema Integrado de Información Agropecuaria (SIIA) del Ministerio de Agricultura, Ganadería y Pesca de la Argentina. 
CUADRO 1

Provincia del Chaco: distribución de los productores de algodón según tamaño, 2002

\begin{tabular}{lccc}
\hline Tamaño & Superficie en hectáreas & Porcentaje de productores & Superficie sembrada con algodón en porcentaje \\
\hline Minifundistas & 0,1 a 10 & 60 & 9 \\
Pequeño-mediano & 10 a 100 & 34 & 41 \\
Grande & Más de 100 & 6 & 50 \\
\hline
\end{tabular}

Fuente: Instituto Nacional de Estadísticas y Censos (INDEC), Censo Nacional Agropecuario 2002.

en el tiempo debido principalmente a cambios en la política nacional y en los precios internacionales. Como suele ocurrir con los productos básicos (commodities), la evolución de la producción se correlaciona con la de dichos precios (véase el gráfico 2).

Desde fines de la década de 1990, la expansión de la producción de soja desplazó significativamente al cultivo del algodón en la provincia (véase el gráfico 3 ). Con la recuperación de la economía (y en particular de la industria textil), la producción de algodón se reactivó a partir de 2003, pero aún se mantiene lejos de sus niveles históricos (véase el gráfico 1).
Monsanto es la única empresa que introdujo semillas de algodón GM en la Argentina a través de una empresa mixta (joint venture), Genética Mandiyú, creada en 1997 entre Monsanto, Delta \& Pine (luego adquirida por Monsanto) y CIAGRO, la principal distribuidora de insumos en el noreste argentino. En 1998, Monsanto obtuvo la aprobación del Ministerio de Agricultura para comercializar una variedad de algodón Bt (resistente a insectos lepidópteros) y en 2001, para comercializar una semilla RR tolerante al glifosato — un herbicida de amplio espectro- cuyo fondo genético proviene de una variedad originalmente desarrollada por el INTA

GRÁFICO 2

\section{Precio internacional y área sembrada en la Argentina}

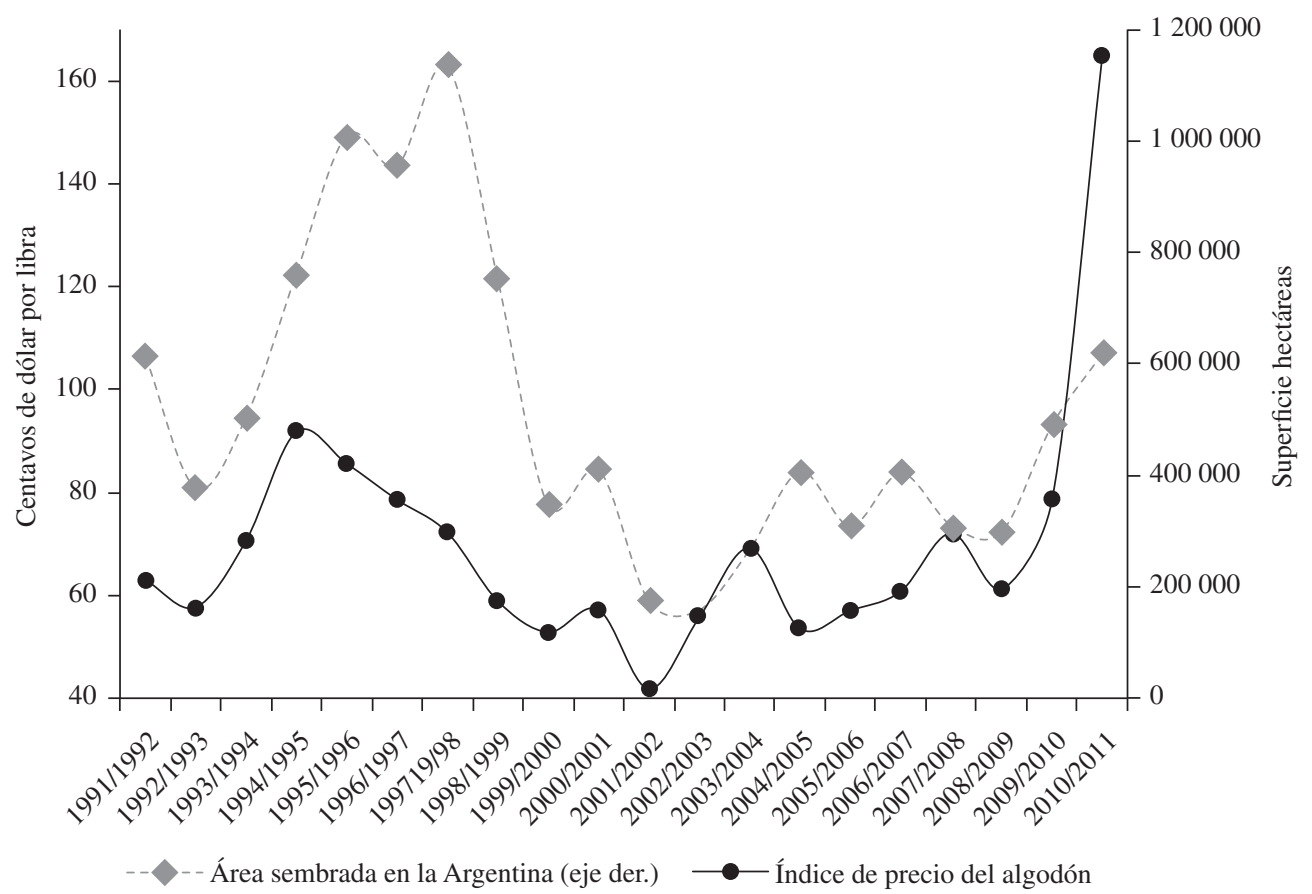

Fuente: elaboración propia sobre la base del Sistema Integrado de Información Agropecuaria (SIIA) del Ministerio de Agricultura, Ganadería y Pesca de la Argentina, para el área sembrada, y de Cotlook Index " $A$ " (http://www.cotlook.com/) para el índice de precio (la fuente internacional más ampliamente utilizada para el mercado de exportación de la fibra de algodón). 


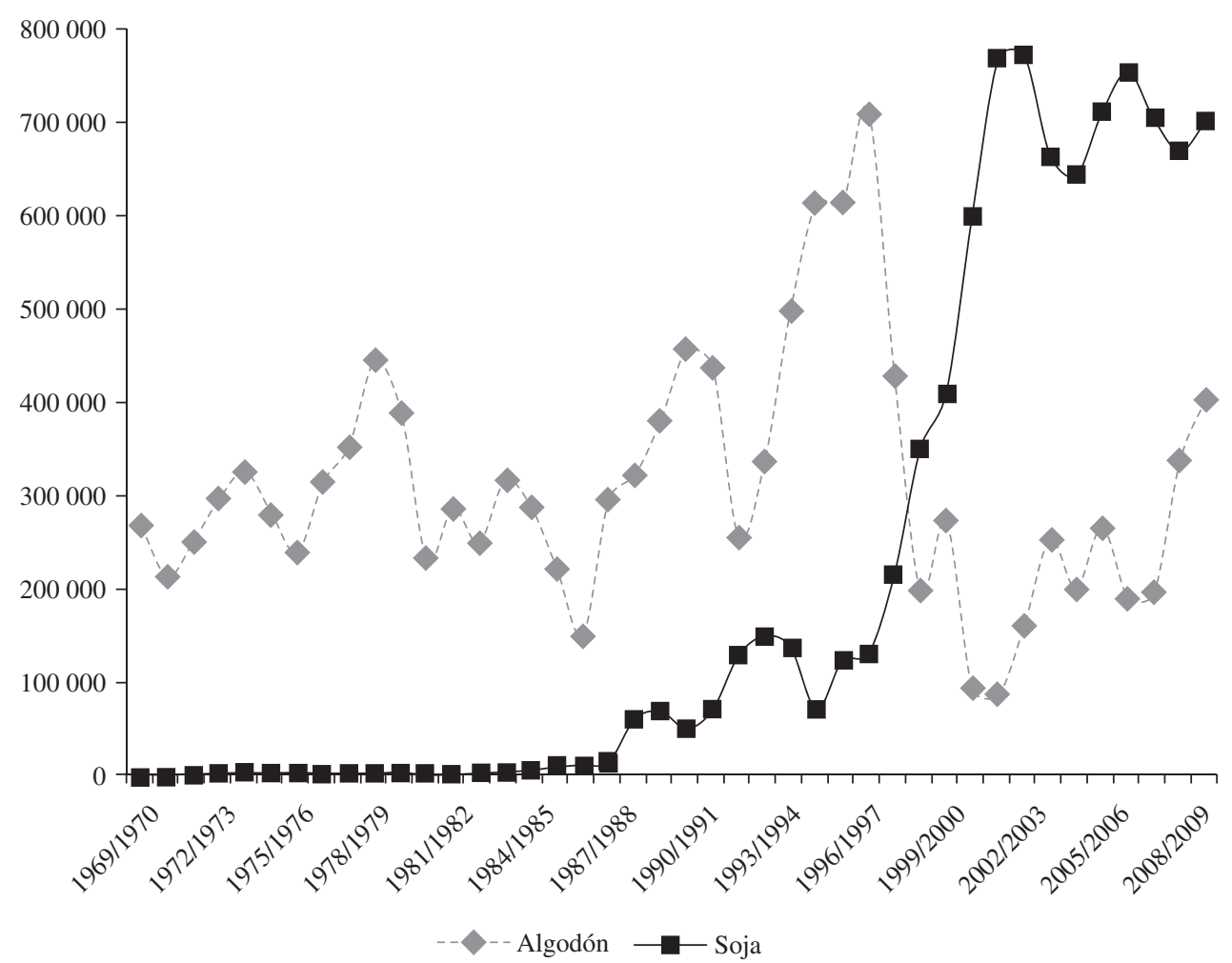

Fuente: elaboración propia sobre la base del Sistema Integrado de Información Agropecuaria siIA) del Ministerio de Agricultura, Ganadería y Pesca de la Argentina.

(Guazuncho). Finalmente, en 2009 obtuvieron aprobación comercial dos variedades que "apilan" los genes Bt y RR de Monsanto (dicha combinación de genes se denomina "evento apilado Bt/RR"). Vale decir, se obtuvieron semillas que son a la vez resistentes a lepidópteros y tolerantes al glifosato. Una se comercializó en dicho año, mientras que la segunda se promovió comercialmente en 2011.

Con la introducción de las semillas de algodón transgénico se transformó el mercado de semillas de algodón. Hasta comienzos de la década de 1990, toda el área sembrada con algodón correspondía a variedades desarrolladas por el INTA. La difusión de semillas GM, especialmente las variedades tolerantes al herbicida y el evento apilado, fue acelerada (véase el gráfico 4) y, dado su carácter autógamo (que permite la auto-fertilización), la semilla pudo ser multiplicada de manera informal, sin autorización de Genética Mandiyú ni control de calidad por parte del Instituto Nacional de Semillas (INASE), expandiéndose muy rápidamente. Según fuentes de la industria, las semillas de algodón GM no certificadas —conocidas como "bolsa blanca"— representaban más del $80 \%$ de las semillas GM plantadas en $2009^{4}$.

\section{Las configuraciones socio-técnicas del algodón en el Chaco}

Los pequeños productores viven en condiciones de extrema precariedad, tanto por la falta de acceso a servicios básicos de vivienda, electricidad y agua, como por la insuficiencia de ingresos. En efecto, la mayoría de las familias de pequeños productores de algodón habitan en viviendas rancho ${ }^{5}$, en condiciones de hacinamiento, y solo algunas de ellas, muy recientemente, han accedido

\footnotetext{
${ }^{4}$ Entrevista realizada con representantes de la industria.

${ }^{5}$ Se trata de viviendas rurales de condición muy austera, con paredes de adobe sin frisar, láminas metálicas, paja o similares en el techo y piso de tierra.
} 
GRÁFICO 4

Argentina: evolución del área sembrada con algodón GM

(Participación porcentual en el área sembrada con algodón)

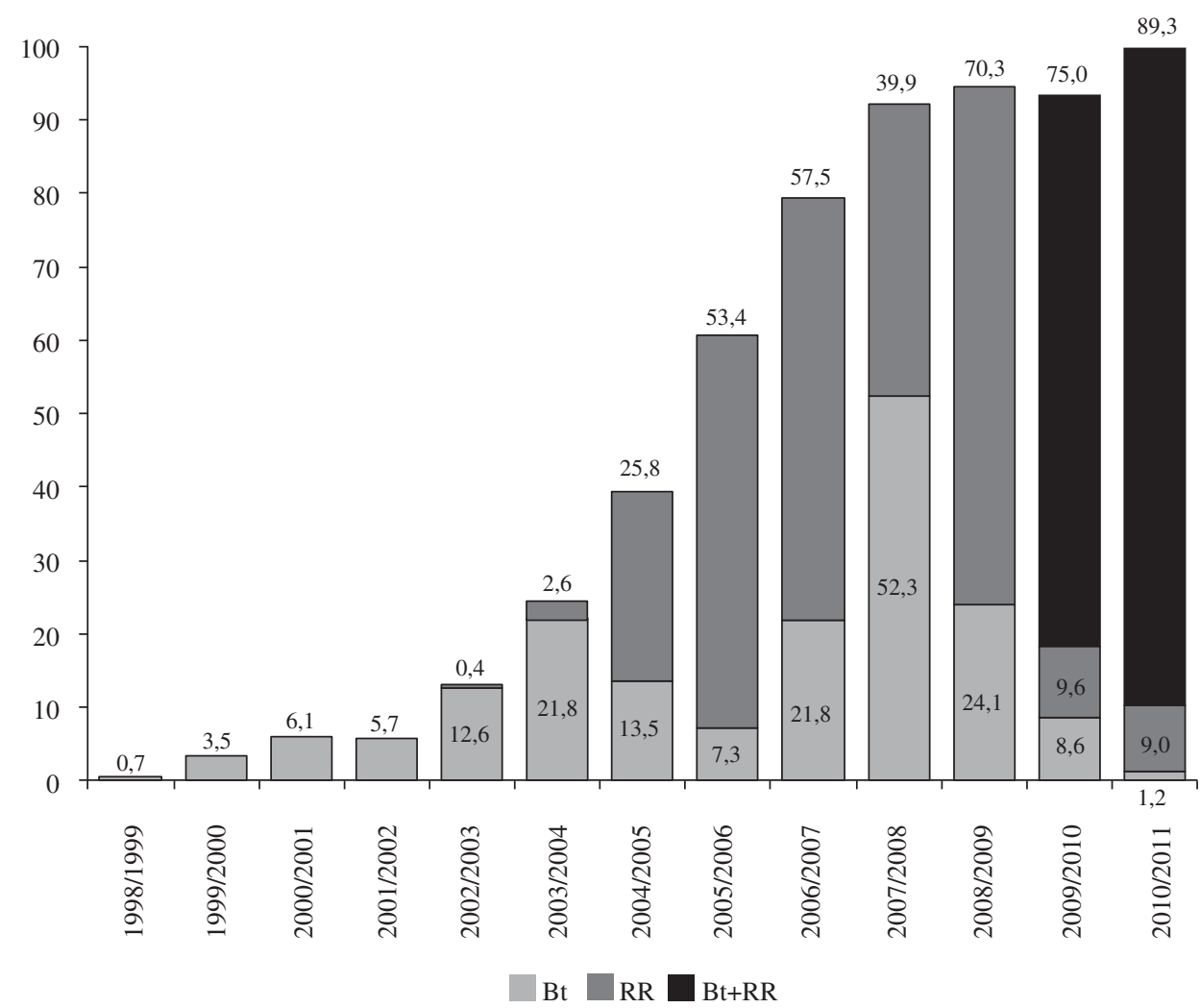

Fuente: elaboración propia sobre la base del Sistema Integrado de Información Agropecuaria (SIIA) del Ministerio de Agricultura, Ganadería y Pesca de la Argentina, para el área sembrada total, y del Consejo Argentino para la Información y el Desarrollo de la Biotecnología (ArgenBio) para la adopción de algodón GM por tipo.

Bt: variedad de algodón resistente a insectos y lepidópteros.

RR: herbicida cuyo fondo genético proviene de una variedad originalmente desarrollada por el Instituto Nacional de Tecnología Agropecuaria (INTA).

a la electrificación rural. No cuentan con agua proveniente de las redes de agua potable, pero además, con frecuencia tampoco disponen de agua de pozo dentro de su predio. Trabajan la tierra para su propia subsistencia: se alimentan con los productos de huerta que cultivan y los animales que crían en su chacra, y suelen encontrar dificultades para vender esta producción en caso de tener excedente, ya que no cuentan con los medios para lograr venderla en los pueblos, generalmente lejanos. El único cultivo que realizan con fines comerciales es el algodón. Con los ingresos obtenidos de su venta adquieren bienes básicos como vestimenta y artículos escolares para sus hijos. En la mayoría de los casos, el trabajo de la tierra es realizado enteramente por la familia. Reciben apoyo de programas públicos locales que les brindan servicios de preparación del suelo, semillas y combustible. Además, por lo general los productores reciben alguna transferencia pública, que llega a representar una alta proporción de los ingresos totales del hogar ${ }^{6}$. El crédito formal no está disponible para ellos y utilizan canales informales para adquirir los insumos a crédito, pagando un elevado interés. Asimismo, suelen ostentar frágiles derechos de propiedad sobre la tierra en la que trabajan

\footnotetext{
${ }^{6}$ Desde el año 2009, los diversos programas nacionales de transferencia de ingresos para los hogares con hijos se unificaron en la Asignación Universal por Hijo para Protección Social (AUH), que transfiere \$220 mensuales por cada hijo(a) menor de 18 años, hasta cinco hijos; y $\$ 440$ por cada hijo(a) discapacitado sin límite de edad.
} 
y viven, lo que les impone una situación adicional de vulnerabilidad.

En este contexto, los pequeños productores de algodón del Chaco enfrentan serios problemas productivos y de rentabilidad. Los rendimientos son bajos sobre todo porque se ven severamente afectados por el picudo del algodonero, una plaga que no es controlada por la tecnología transgénica ${ }^{7}$. A su vez, los suelos en que producen están deteriorados por las deficientes prácticas de manejo de suelos (no realizan rotación de cultivos ni utilizan fertilizantes). La asistencia técnica que reciben se centra en otros cultivos y por lo general se desarrolla en los pueblos (bajo la forma de reuniones informativas y otras actividades "de escritorio") o en campos de demostración, pero no en la chacra de los productores.

La escasa rentabilidad de los pequeños productores no se debe únicamente a los bajos rindes, sino también a su posición en la cadena de comercialización. El algodón cosechado es vendido en bruto y ellos deben aceptar el precio ofrecido por los intermediarios que lo retiran de la chacra. Esto se explica por tres factores: i) se hallan endeudados con este intermediario que comúnmente se trata de la misma persona que les adelantó los insumos a crédito, cobrándoles una elevada tasa de interés; ii) encuentran dificultades de transporte para elegir otros mercados; iii) no pueden vender la producción en mercados donde se exige inscripción fiscal, por no estar legalmente inscritos ${ }^{8}$. A esto se suma su urgencia por vender la producción, debido a que necesitan ese ingreso para la subsistencia del hogar. En muchos casos,

\footnotetext{
${ }^{7}$ El picudo es una plaga específica del continente americano, que se alimenta y reproduce en las cápsulas del algodón impidiendo la floración. En algunos estudios científicos se sugiere que la difusión de la plaga podría estar vinculada a la reducción de fumigaciones que ocurrió como consecuencia del algodón Bt (y del Bt/RR) (Grossi-de-Sa y otros, 2007; CCIA, 2009).

${ }^{8}$ En la actualidad, para vender la producción cosechada directamente a las cooperativas o a quienes realizan el proceso de desmote (ver definición en nota 9) se requiere inscripción fiscal, a fin de poder emitir facturas. Pero los pequeños productores generalmente no están registrados en el fisco, dado que les resulta muy oneroso realizar aportes regulares. Por lo tanto, continúan vendiendo el algodón en bruto a través de canales informales a productores más grandes registrados o acopiadores locales, que luego lo comercializan con la desmotadora.
}

las cooperativas operan como un intermediario, tanto en calidad de comprador de la cosecha como proveedor de insumos, especialmente semillas, ya que en el proceso de "desmote" " usualmente las recuperan y se las venden nuevamente al productor ${ }^{10}$. Esta práctica reduce el poder germinativo de la semilla e incrementa la incertidumbre acerca de la identidad de las variedades.

Sin embargo, cabe resaltar que, a pesar de su precaria situación y de su escasa rentabilidad, los pequeños productores tienen un apego cultural al algodón. Han nacido y se han criado con el algodón y aprendieron a cultivarlo viendo cómo lo hacían sus padres. Es parte de su identidad. Además, para ellos el algodón, a diferencia de otros cultivos, funciona como moneda: pueden cosechar pequeñas cantidades y siempre encontrarán a quien vendérselo, aunque obtengan un precio modesto.

La situación de los productores mayores es muy diferente. Ellos utilizan maquinaria moderna y mano de obra contratada. Por lo general, combinan la producción de algodón con la de soja y en algunos casos con la de girasol, maíz o sorgo. La soja en particular puede representar una alta proporción del área sembrada. Los productores menores dentro de este grupo son empresas familiares, pero los grandes suelen ser organizaciones de tipo corporativo (Arza y otros, 2010) cuyos inversores normalmente no están involucrados en persona con la vida rural. Por lo general, estos productores tienen su propia desmotadora y adoptan tecnologías de frontera, incluido el paquete tecnológico completo asociado a las semillas GM (véase la descripción en el recuadro 1). Este grupo es el principal cliente de Genética Mandiyú, aunque también multiplican su propia semilla.

\footnotetext{
${ }^{9}$ Proceso productivo en que se obtiene fibra de algodón a partir del algodón cosechado en bruto, separando la fibra de las semillas y de otros desperdicios que se arrastran de la cosecha. Se realiza por medio de una máquina desmotadora.

${ }^{10} \mathrm{Si}$ bien las cooperativas fueron fundadas para mejorar el poder de negociación de los productores vis-à-vis con los grandes compradores de fibra de algodón, y también para obtener mejores precios al comprar conjuntamente insumos clave como el gasóleo, en la actualidad la actividad de estas cooperativas no se diferencia de la de otros intermediarios.
} 
RECUADRO 1

\section{El paquete tecnológico completo}

Para maximizar los rendimientos y la rentabilidad de su adopción, se recomienda que las semillas GM estén acompañadas por determinadas prácticas e insumos. Aunque es posible adoptar solo algunos de sus componentes, el paquete tecnológico completo incluye: semillas GM adquiridas en el mercado formal; siembra directa en surco estrecho (0,48-0,5 metros); herbicidas e insecticidas para aplicar a lo largo del ciclo del cultivo; reguladores de crecimiento; defoliantes y cosecha mecánica empleando la cosechadora stripper adaptada a surco estrecho. La utilización de este paquete requiere de una escala mínima que justifique la mecanización y conocimientos técnicos. También se necesitan recursos para la compra de insumos. Los pequeños productores de algodón, que no tienen acceso a crédito formal y cuentan tan solo con su trabajo y el de su familia, siguen sembrando con el sistema convencional (a un metro) y cosechan manualmente. En el siguiente cuadro se presenta una estimación del diferencial de rendimientos y rentabilidad entre quienes utilizan el paquete tecnológico completo y quienes no lo emplean:

Productores que utilizan el paquete completo

Productores que no lo utilizan

Rendimientos (ton/ha)

Precio del algodón en bruto (AR\$/ton)

Costo de la semilla (AR $\$ / h a)$

Porcentaje de fibra

2,9
800
630
25

800

25
1

1000

80

Fuente: M.G. Elena, “Costo de producción por hectárea de algodón”, Instituto Nacional de Tecnología Agropecuaria (INTA), 2010 [en línea] http://inta.gob.ar/documentos/costo-de-produccion-por-hectarea-de-algodon-2009-10-para-surcos-estrechos0-52m-1/ y talleres con productores organizados por los autores. Estimaciones para la campaña 2009/2010.

AR\$: pesos argentinos.

En algunos estudios del INTA, Estación Experimental Agropecuaria (EEA) Sáenz Peña, se compararon los márgenes que se obtienen combinando distintos elementos del paquete. En Elena, Íbalo y Gesualdo (2006) se estima el beneficio adicional de sembrar en surco estrecho para siembra directa (SD) y siembra convencional (SC). Los resultados indican que la siembra en surco estrecho produce un beneficio adicional de $\$ 818,37$ y $\$ 553,55$ por hectárea para SD y SC, respectivamente.

De manera similar, Elena, Ybran y Lacelli (2008) analizan los costos de producción del algodón utilizando diferentes alternativas de siembra y cosecha, y distintos escenarios de precios. Concluyen que la siembra en surco estrecho y la cosecha stripper tienen resultados más competitivos que la cosecha manual o picker y que, para el peor escenario de precios, la única alternativa rentable surge de la combinación de siembra en surco estrecho y cosechadora stripper. 


\section{III}

\section{Repercusión de la adopción del algodón GM por parte de pequeños productores del Chaco}

\section{Los beneficios de la adopción de las semillas GM según la literatura}

Uno de los trabajos más populares sobre el impacto de la adopción del algodón GM en la Argentina es el de Qaim y de Janvry (2005), que se basa en encuestas realizadas a una muestra de productores de algodón durante las campañas agrícolas de 1999-2000 y 2000-2001. Cabe destacar que, en el momento de realizar el estudio, el número de usuarios de semillas de algodón GM era aún reducido. La muestra contiene 298 observaciones, de las cuales 125 corresponden a productores de más de 90 hectáreas. Entre ellos había en ese momento 87 usuarios de algodón Bt. La muestra también contiene observaciones para 173 productores con extensiones menores de 90 hectáreas, entre los cuales no había usuarios de la tecnología. Los autores estiman un modelo econométrico para evaluar en qué medida la adopción del algodón $\mathrm{Bt}$ aumentó los rendimientos y redujo el uso de pesticidas entre sus usuarios. Concluyen que el número de aplicaciones de pesticida y la cantidad utilizada disminuyen significativamente cuando se siembra la semilla Bt. A su vez, la tecnología incrementa los rendimientos en $500 \mathrm{~kg}$ por hectárea, en promedio. De acuerdo con los autores, los efectos en los rendimientos son mayores que los hallados para otros países donde se adoptó la tecnología, como China o los Estados Unidos de América. La explicación que encuentran para este efecto diferencial es que el control de plagas en la Argentina, previo a la incorporación de la semilla, era deficiente: la cantidad de pesticida aplicado con la semilla convencional era menor que el recomendado, por lo tanto, la adopción del algodón Bt aumentó los rendimientos más de lo que lo habría hecho si el control de plagas previo hubiera sido mayor ${ }^{11}$. Por esta misma razón, y a pesar de que

\footnotetext{
11 Más aún, los autores destacan que este resultado podría estar subestimado debido a la imposibilidad de controlar por el germoplasma (fondo genético): las variedades Bt que se lanzaron comercialmente no fueron específicamente desarrolladas para el suelo argentino, como sí lo eran las variedades convencionales desarrolladas por el INTA y comercializadas hasta ese momento. Por lo tanto, si se controlara por este factor, el efecto vinculado exclusivamente al gen del Bt podría ser incluso mayor.
}

los pequeños productores no habían adoptado la semilla Bt en el momento de realizar el estudio, los autores infieren que esa tecnología resultaría particularmente efectiva para ellos ${ }^{12}$, debido a que el control de plagas que suele realizar este grupo es incluso más insuficiente.

Otro trabajo en que se analiza la repercusión del algodón GM en términos de productividad y rentabilidad es el de Trigo y Cap (2006), quienes también emplean datos de la campaña 2001-2002. En este trabajo se toman resultados de Elena (2001) — que estima que el algodón Bt incrementa los rendimientos en un 30\%para analizar la distribución de los beneficios entre los agricultores, la industria semillera y el Estado. Sobre la base de promedios, los autores concluyen que el $86 \%$ de los beneficios son apropiados por los agricultores y que los beneficios de la (única) empresa semillera son bajos debido a que el $66 \%$ de la semilla utilizada es de "bolsa blanca".

Diez años después de las investigaciones de Qaim y de Janvry (2005) y Trigo y Cap (2006), la situación de la adopción del algodón GM en el Chaco es marcadamente diferente. En primer lugar, hay nuevas variedades: además de la semilla Bt existen ahora la semilla RR y el evento "apilado", que se encuentran ampliamente difundidos, mayormente a través de canales informales. En segundo lugar, las semillas convencionales prácticamente han desaparecido del mercado y se presume que las pocas que circulan tienen un alto grado de contaminación con material transgénico. En tercer lugar, el picudo del algodonero se ha expandido y representa en la actualidad la mayor amenaza para la producción de algodón en la provincia.

Por lo tanto, y dado que la gran mayoría de los productores grandes, medianos y pequeños siembran semillas de algodón GM, resulta sobre todo relevante analizar si su adopción por parte de los pequeños productores ha tenido los efectos esperados en términos de rendimientos y rentabilidad.

\footnotetext{
12 En el trabajo se clasifica a los productores de la muestra como pequeños o grandes en función de si la superficie que cultivan supera o no las 90 hectáreas.
} 
Ese es el objetivo de este trabajo. Sobre la base del enfoque conceptual de la configuración socio-técnica de la tecnología, se analizan las prácticas productivas en relación con el uso de semillas GM. La sección III, número 2 , se centra en las prácticas productivas relacionadas con los rendimientos, mientras que la sección III, número 3, se focaliza en la rentabilidad. En ambas se describen rupturas y continuidades como consecuencia de la adopción de la tecnología GM. Puesto que no existen estadísticas de rendimientos y rentabilidad desagregadas por tamaño, se ha recurrido a la información provista por la aplicación de metodologías cualitativas. Sin ánimo de generalizar, para ilustrar los principales argumentos se presentan citas textuales de los productores y de otros actores, que provienen de los talleres participativos y las entrevistas realizadas.

\section{Prácticas productivas y rendimientos}

Actualmente existe una amplia difusión de la semilla GM entre los pequeños productores. Las semillas a las que acceden son, sin embargo, de dudosa calidad, ya que en todos los casos se trata de semillas de la llamada "bolsa blanca", que fueron adquiridas informalmente o distribuidas en forma gratuita por el gobierno local ${ }^{13}$.

Más allá de la adopción generalizada de las semillas GM, los pequeños productores no han adquirido maquinaria ni han cambiado sus técnicas de siembra. Incluso, continúan con la práctica del monocultivo, que genera un deterioro creciente de los suelos.

Para la preparación de la tierra deben recurrir a servicios de terceros: por lo general, dependen de que algún vecino con tractor acceda a proveerles el servicio a cambio del combustible que reciben gratuitamente del gobierno ${ }^{14}$. Si la municipalidad posee un tractor, utilizan ese servicio para la preparación del suelo, pero no siempre está disponible porque son muchos los productores entre los que se sortea el uso del único tractor que suele poseer el municipio ${ }^{15}$.

\footnotetext{
${ }^{13}$ Hace algunas campañas, el gobierno provincial — que históricamente entregaba de forma gratuita a los pequeños productores semillas de algodón convencional- ha delegado la compra de semillas en los municipios, que adquieren y distribuyen semillas GM no certificadas. 14 "Ahora tenemos los 'vales' de gasóleo, pero tenemos que esperar que alguno con tractor termine de trabajar en su campo y ver si quiere venir a las chacras a cambio de esos vales. No todo el mundo quiere venir a las chacras chicas porque es más costoso y puede haber problemas". Pequeño productor, Sáenz Peña.

15 "A nosotros se nos atrasa todo porque el municipio es el encargado de 'romear' (arar) las tierras y al ser 30 las asociaciones, se sortean y nunca llega a algunas asociaciones. $\mathrm{O}$ sea, el municipio cuenta con un tractor y ahora está por comprar otro". Pequeño productor, Sáenz Peña.
}

Las técnicas de cosecha no han cambiado con la adopción de la tecnología GM. Los pequeños productores continúan cosechando pequeñas cantidades en cada floración y vendiendo el algodón en bruto inmediatamente porque necesitan adquirir bienes básicos de consumo ${ }^{16}$. El algodón sigue funcionando para ellos como moneda porque en la provincia puede venderse muy fácilmente a acopiadores o intermediarios locales. La cosecha es manual y en ella trabaja toda la familia ${ }^{17}$. Sin embargo, desde el éxodo de la población joven, muchas familias no cuentan con miembros suficientes en el momento de la cosecha y necesitan contratar cosecheros, lo que deteriora aún más su reducida rentabilidad.

En cuanto a las técnicas de siembra, los pequeños productores de todas las localidades visitadas declararon que no han modificado la distancia entre surcos $(0,7-1$ metro). Consultados acerca de las razones por las que no sembraban en surcos estrechos, tanto los productores como los técnicos del INTA adujeron que enfrentan dificultades para acceder a los insumos y la maquinaria requeridos para sembrar y cosechar a esa distancia ${ }^{18}$. Más allá de esta restricción, durante los talleres también se identificó una percepción común entre los pequeños productores de que los rendimientos en surco estrecho son más bajos porque la planta "carga menos"19, a pesar de que existe consenso entre los técnicos del INTA consultados de que los rendimientos son superiores.

Esta diferencia entre la percepción de los productores y la opinión técnica sirve para ejemplificar cierta dificultad de la asistencia técnica para acceder a los

\footnotetext{
16 "La otra es porque, familiarmente, lo que se puede juntar en una semana de algodón, de lunes a sábado juntamos 2.000 ó 3.000 kilos y bueno, tenemos que vender porque necesitamos para ir pasando. Lo que se va juntando vamos vendiendo por nuestra necesidad. No es que uno puede juntar 20 toneladas, no es lo mismo que vender 2.000 kilos". Pequeño productor, Quitilipi.

17 "Y el pequeño productor, nosotros siempre anduvimos con la familia nomás. Yo sembraba dos hectáreas. Cuando sembraba la verdura, decía: bueno, me junto con mi familia y resulta que hoy coseché las dos hectáreas y es una plata que vos hacés dentro de la familia. No pagás nada más que la familia hace el trabajo y de eso uno vive". Pequeño productor, Sáenz Peña.

18 "Surco estrecho tenés que tener plata para la tecnología. El defoliante... Tenés que tener un tamaño para que vos puedas entrar con las máquinas. Ellos cosechan a mano y a los 52 años no podés cosechar a mano". Agente del INTA, entrevista septiembre de 2010. 19 "Que me disculpe la gente del INTA, pero el surco estrecho es discutible: hay que hacer bien los números. Yo hablé con gente que hizo las dos cosas y dice que tenés que hacer muy chiquitos los números y no sabés cuál te conviene. Porque hablamos de tres toneladas por hectárea, pero con un rinde de $20 \%$ a $22 \%$ y yo cosecho con la otra máquina o a mano y en un año normal me da $37 \%, 38 \%, 40 \%$. Entonces no sé. Y yo para desmotar ese algodón stripper cobro $\$ 100$ más". Pequeño productor y miembro de una cooperativa, Quitilipi.
} 
pequeños productores ${ }^{20}$. Más aún, es probable que desde la introducción del algodón GM, la asistencia técnica del INTA en este cultivo se haya reducido y reorientado hacia otras actividades productivas consideradas prioritarias por la institución.

Existen varios motivos que podrían explicar este cambio de prioridades. En primer lugar, a partir del año 2001 se produjo un viraje en la estrategia de extensión del INTA, de la transferencia de tecnología a proyectos de "innovación tecnológica", que por lo general persiguen simultáneamente objetivos sociales, ambientales y necesidades tecnológicas (Alemany, 2003). En la práctica, estos proyectos de extensión han dado prioridad a la producción de frutas, vegetales y ganado, antes que a cultivos industriales, en concordancia con los principios de soberanía alimentaria.

En segundo lugar, los agentes del INTA están sobre todo preocupados de las condiciones de los suelos en la región, que demandan una urgente estrategia que incluya diversificar la producción. Los pequeños productores son reacios a la diversificación más allá del algodón y de alimentos para el autoconsumo. De acuerdo con los técnicos del INTA, esta reticencia empeora la calidad de los suelos, lo que a su vez reduce los rindes ${ }^{21}$. Consultados al respecto, los pequeños productores mencionaron fundamentalmente la falta de mercados donde vender producciones alternativas, así como las virtudes del algodón: es no perecedero, encuentra mercado fácilmente y es resistente a condiciones climáticas adversas 22 .

En tercer lugar, conviene resaltar otro aspecto que afecta al protagonismo del INTA en el mercado de semillas y que se relaciona con la privatización del conocimiento. Antes de la introducción de los GM en muchos países en desarrollo, la Argentina entre ellos, el fitomejoramiento ${ }^{23}$ era realizado en gran medida

20 "El Estado nunca se ocupó de los más chicos. Jamás vino un técnico acá a decirnos qué semilla, jamás. Los técnicos están en Quitilipi, en Sáenz Peña, pero acá jamás un técnico nos ayudó”. Pequeño productor, Quitilipi.

"La gente del INTA hace alguna charla acá, no van a la chacra. Los grandes tienen sus técnicos, pagados, tienen el INTA, todo tienen ellos". Pequeño productor, Quitilipi.

21 "Hay que ver el suelo también. Está rindiendo menos porque hace 30 años que hacen algodón. Hay que empezar a rotar”. Agente del INTA. 22 "Yo defiendo al algodón, voy a morir con algodón, porque no hay nada que aguante como el algodón, para empezar en esta zona. Si yo me voy a hacer 10 hectáreas de girasol, soja o trigo, ni hablemos, para vender tengo que hacer milagros: hay que inscribirse en la Oficina Nacional de Control Comercial Agropecuario (ONCCA) [...] para nosotros es imposible. Y si vas con la verdura: a quién le vendés? ¿Dónde está el mercado? Si los 900 productores hacemos media hectárea de zapallo cada uno. ¿Dónde vamos?”. Pequeño productor, Quitilipi.

${ }^{23}$ Se refiere al mejoramiento convencional de plantas a partir de la exploración de la varianza genética (creada deliberamentemente o por los propios productores e instituciones públicas de investigación. La difusión de la tecnología GM y el posterior fortalecimiento de los derechos de propiedad intelectual (DPI) pusieron un claro límite a dichas prácticas (McIntyre y otros, 2008) ${ }^{24}$. Debido a que el desarrollo de germoplasma está sujeto a economías de escala, y dado que la mayoría de las empresas que producen semillas GM son actores globales que optimizan las ventas a nivel mundial, estas firmas persiguieron activamente estrategias de estandarización. A consecuencia de esta tendencia se redujo drásticamente la diversidad de variedades disponibles en el mercado. Tanto es así que en la actualidad se siembran solo tres variedades y dos de ellas provienen de fondos genéticos importados ${ }^{25}$. Antes de la difusión de los transgénicos, en cambio, el mercado de semillas de algodón estaba dominado por las variedades convencionales desarrolladas por el INTA. La institución no solo realizaba investigación para el desarrollo de opciones tecnológicas adaptadas a la región y mejoras y diversificación del producto, sino que también asumía la responsabilidad de la multiplicación y, a veces, del proceso de comercialización de las semillas. De hecho, hasta la década de 1990, la producción de semillas del INTA la realizaban "asociaciones cooperadoras" de esta institución o semilleros privados que firmaban acuerdos con ella bajo el esquema de los acuerdos de vinculación tecnológica. A medida que la tecnología GM se difundía, las empresas semilleras finalizaron (o no renovaron) sus acuerdos con el INTA hasta la actualidad, en que solo queda una asociación cooperadora que produce variedades en los campos de la institución y una sola empresa semillera que ha solicitado licencia para multiplicar semillas del INTA destinadas a la campaña de $2011^{26}$.

Debido a lo anterior, mientras que en el pasado el INTA ponía especial interés en la difusión y la correcta utilización de sus variedades, hoy, si bien sigue siendo la principal institución a nivel nacional que realiza investigación específica en algodón ${ }^{27}$, las variedades

hallada en poblaciones silvestres), seleccionando los individuos más deseables según diferentes características agronómicas.

${ }^{24}$ En la Argentina, Rossi (2006) afirma que la intensa propagación de cultivos GM implicó la privatización de la producción y difusión de conocimiento.

25 Para la campaña 2011-2012 ha sido lanzada una nueva semilla GM que contiene el evento apilado sobre una variedad antigua (registrada en 1996) del INTA.

${ }^{26}$ Entrevistas con agentes del INTA.

27 Entre los diversos proyectos de investigación sobre tecnología para el algodón actualmente vigentes en el INTA, merece señalarse un convenio de vinculación tecnológica que la institución firmó con las provincias algodoneras en 2009. El objetivo es generar conocimientos y tecnologías no contaminantes para el control del picudo y desarrollar 
que desarrolla no se venden en el mercado. La asistencia técnica sobre las variedades GM que se utilizan es realizada principalmente por técnicos privados, que son contratados por grandes productores. También Genética Mandiyú provee "servicio técnico" y "atención al cliente" para sus clientes. Los pequeños productores, que no tienen recursos para contratar servicios técnicos privados ni son clientes de Genética Mandiyú porque adquieren sus semillas en el mercado informal, no suelen recibir asistencia técnica.

En síntesis, más allá de la amplia adopción de las semillas de algodón GM, los pequeños productores no han cambiado sus técnicas de siembra y cosecha, las máquinas que usan no han sido actualizadas, no suelen recibir asistencia técnica y no han diversificado la producción.

No obstante, no todo ha permanecido igual. En primer lugar, como ya se mencionó, el picudo del algodonero se ha convertido en uno de los problemas clave que explican la caída en los rendimientos, en especial para los pequeños productores que no pueden afrontar el costo de su control. La gravedad del problema radica en que es una plaga muy destructiva debido a su alta tasa de reproducción y la ausencia de enemigos naturales, y porque no es controlada por el gen Bt disponible en las semillas comerciales. Si bien existe un conjunto de prácticas tendientes a limitar la incidencia del picudo (por ejemplo, concentrar el período de siembra, reducir el ciclo de crecimiento de la planta, destruir los rastrojos inmediatamente después de la cosecha y evitar los rebrotes), dichas prácticas no están difundidas entre los pequeños productores. Para ellos, el momento de la siembra está determinado por factores climáticos y por la disponibilidad de semillas; la siembra en surcos estrechos para acortar el ciclo del cultivo requiere maquinaria a la que no tienen acceso; la destrucción inmediata del rastrojo no se realiza por falta de combustible y porque pueden aprovecharlo como alimento para el ganado; no evitan los rebrotes porque los pueden cosechar y obtener un ingreso extra; y tampoco aplican la cantidad de insecticidas que podría ayudar a controlarlo porque son muy costosos.

un manejo integrado. Las actividades del proyecto se realizan en el marco de cinco módulos que enfrentan el problema del picudo, donde participan más de 40 investigadores y auxiliares de la institución. Los módulos comprenden desde el mejoramiento convencional del algodón hasta soluciones biotecnológicas y hay un módulo específico dedicado a estudiar aspectos de la propiedad intelectual relacionados con la temática de investigación.
En segundo lugar, a partir del uso de semillas con el gen RR, la mayoría de los productores dejó de carpir ${ }^{28}$ o de contratar carpidores. Esto es algo muy valorado por casi todos los productores, especialmente porque no es fácil conseguir carpidores 29 .

En tercer lugar, vinculado a lo anterior, la difusión del uso de herbicidas de amplio espectro es uno de los principales cambios en las prácticas productivas como consecuencia de la introducción de la semilla GM.

En cuarto lugar, hubo varias referencias al problema del éxodo rural, en particular entre la gente joven. Las principales razones que explican este éxodo son los problemas de infraestructura y la falta de oportunidades ${ }^{30}$. El éxodo está provocando una escasez de mano de obra que retrasa la cosecha e incrementa la exposición al picudo.

En síntesis, en esta subsección se ha mostrado que los pequeños productores adoptan una versión incompleta del paquete tecnológico GM descrito en el recuadro 1. Ellos no incorporan los elementos que presentan economías de escala (maquinaria), los que exigen capital de trabajo (la mayoría de los insumos), las mejores prácticas de siembra (surco estrecho), ni realizan un control de plagas adecuado, especialmente en el caso del picudo del algodonero. Tampoco logran detener el deterioro de los suelos a través de la diversificación de los cultivos, debido a la falta de mercados para productos alternativos al algodón. Algunos aspectos de la gestión de la tecnología antes provistos por el INTA ahora son brindados mayormente por privados o por la empresa productora de semillas GM, a quienes los pequeños productores no acceden. En definitiva, a partir del análisis de las prácticas productivas realizado, no se desprende que los pequeños productores de algodón hayan podido mejorar los rendimientos mediante la adopción de semillas GM, como reporta la literatura para los productores de mayor envergadura.

\footnotetext{
${ }^{28}$ Limpiar la tierra para sacar las malas hierbas, desmalezar. 29 "El productor, a la hora de carpir, está con cero pesos, por eso es difícil conseguir carpidores, eso es un problema". Pequeño productor, Villa Berthet.

30 "Se redujo la mano de obra familiar... Esa superficie no la pueden cosechar solos y no hay mano de obra... Eso hace que la cosecha en lugar de terminarse en 30 días se prolongue en el tiempo". Agente de estación experimental del INTA, septiembre de 2010.

"A mí también me parece que en el campo no se están dando las condiciones de vida para que el chico se quede: tenés luz cara, agua más o menos, la EGB (Educación General Básica o escolaridad primaria) hasta sexto grado y qué vas a hacer...". Pequeño productor, Quitilipi.
} 


\section{Poder de negociación en la cadena de comer- cialización y rentabilidad}

La rentabilidad de la producción de algodón resulta de la ecuación entre costos e ingresos. No se dispone de información cuantitativa que sería la adecuada para evaluar cambios en dichas variables a partir de la introducción de las semillas GM. Por consiguiente, el análisis se debe limitar a la argumentación analítica que se desprende de la evidencia cualitativa. Con esas herramientas se analiza a continuación el impacto que la difusión de las semillas GM tuvo en los costos, los ingresos y el poder de negociación (que media entre ambas variables) de los pequeños productores.

\section{a) Los costos}

En el paquete tecnológico se incorporan nuevos insumos (principalmente herbicidas, pero también defoliante y reguladores de crecimiento), mientras que se reducen los costos laborales (sobre todo en la carpida, pero también en el control de plagas) y los costos de los pesticidas que dejan de aplicarse. Como se ha dicho, según la literatura, el balance es favorable.

Sin embargo, considerando las prácticas de los pequeños productores, no está claro que los costos medios se hayan reducido también para ellos. Por una parte, las semillas se han vuelto más caras, incluso en el mercado informal, y además requieren nuevos insumos como el herbicida ${ }^{31}$. Por otra, lo más frecuente es que en la producción de algodón participe toda la familia y que solo excepcionalmente se recurra a la contratación de trabajadores $^{32}$. Sin oportunidades alternativas que cubran el tiempo de las labores del trabajo familiar suspendidas, no es incuestionable que la tecnología produzca un ahorro económico para este grupo.

Finalmente, los pequeños productores por lo general no aplicaban pesticidas con las semillas convencionales, de modo que tampoco experimentarían una reducción de costos en este sentido.

\section{b) Los ingresos}

El ingreso que recibe el productor depende de los rendimientos y del precio del algodón cosechado. En

\footnotetext{
31 "El año pasado ordenamos una cantidad de semillas, las compramos $\mathrm{y}$ al final se dejaron todas porque la gente no quiere sembrar porque los costos son muy altos [...]. Además, es muy caro! No estoy seguro de que este paquete tecnológico es conveniente para productores de menos de 50 hectáreas". Representante del gobierno, Pampa del Indio. 32 "Las semillas transgénicas son muy caras y algunas veces no podemos comprarlas. Entonces probamos con la convencional y por lo menos no tenemos tanto gasto; hacemos todo el trabajo con la familia”. Pequeño productor, Pampa del Indio.
}

la sección III se discutió el impacto del uso de semilla GM en los rendimientos, concluyéndose que no resulta evidente que los pequeños productores hayan percibido aumentos en estos a partir del uso de dicha tecnología. Con respecto al precio del algodón cosechado, este no se ha visto favorablemente afectado por la introducción de los GM, ya que se define en el mercado internacional ${ }^{33}$. Además, el pequeño productor suele vender la cosecha en bruto, y por lo tanto las características de la fibra, que al cosecharse manualmente suele ser mejor que la que se consigue por cosecha mecánica, no inciden en el precio que recibe ${ }^{34}$.

\section{c) Poder de negociación}

Como se dijo anteriormente, los pequeños productores se encuentran atrapados en la cadena de comercialización, en particular por los intermediarios que les venden insumos a crédito — que se paga a un elevado interés en el momento de la venta de la cosecha ${ }^{35}$. En general, no pueden elegir a quién comprar los insumos, ya que no tienen cómo adelantar su pago ni acceso al mercado de crédito. Tampoco pueden escoger a quién vender porque están endeudados con el proveedor que les comprará la cosecha ${ }^{36}$.

Se puede argumentar que la difusión del algodón GM ha debilitado el ya reducido poder de negociación de los pequeños productores, porque ahora necesitan más insumos que antes (dependen más que antes de intermediarios) y porque los mercados informales se han extendido.

Aunque los mercados informales de semillas existían con anterioridad a la difusión de las semillas GM, los pequeños productores tenían la opción de comprarlas

\footnotetext{
$33 \mathrm{Si}$ algo pudiera decirse, tal vez lo contrario sería cierto debido a la pérdida de diversidad varietal a la que condujeron los transgénicos, lo que puede haber incidido negativamente en la calidad de la fibra. En la actualidad, la mayor proporción del algodón que se produce proviene de fondos genéticos importados, que por lo tanto no son los más aptos para las condiciones agronómicas y climáticas de la región. ${ }^{34} \mathrm{La}$ falta de retribución a la calidad es importante en el caso de los pequeños productores que realizan cosecha manual. El porcentaje de fibra del total cosechado es mayor con cosecha manual (porque tiene menos desperdicio) que con cosecha mecánica. Al vender el algodón en bruto el pequeño productor pierde percibir este diferencial. "Lamentablemente en nuestro país por ahora la calidad sigue siendo una prédica, lamentablemente no se paga la calidad. Todo nuestro sistema de comercialización, si puede no pagar la calidad no la paga". Agente del INTA, entrevista, septiembre de 2010.

35 "Por el veneno [glifosato] que cuesta \$200, nos cobran \$600". Pequeño productor, Quitilipi.

36 “Te compran a tanto, si te gusta...". Pequeño productor, Quitilipi. "Lo que pasa es que por más que sea lindo te pagan lo que quieren, nos tienen presos". Pequeño productor, Quitilipi.
} 
formalmente ${ }^{37}$. Además, la interacción con los semilleros locales podía permitirles conocer las características agronómicas de la semilla y obtener su asesoramiento técnico. Las semillas convencionales eran en su mayoría variedades del INTA y los semilleros formales, como ya se mencionó, estaban en estrecha conexión con la institución, que no solo había obtenido la tecnología, sino que también asumía responsabilidades en su difusión. En consecuencia, es probable que los pequeños productores estuvieran mejor informados respecto de las variedades disponibles, lo que mejoraba su posición para negociar.

Desde la introducción de la tecnología GM, el papel del INTA en el sistema de semillas se ha debilitado y el tamaño del mercado formal (tanto en términos de la cantidad de semilleros formales, como en la proporción de ventas formales) se ha reducido significativamente. $\mathrm{Si}$ bien al principio solo los grandes productores demandaban semillas GM, a medida que el mercado informal creció, también los pequeños pudieron adoptarlas.

Ante esta situación, en el año 2008, distintos actores del mercado del algodón acordaron firmar un compromiso para ordenar el mercado de semillas (es decir, para controlar la multiplicación de semillas y reducir el tamaño del mercado informal). Por medio de dicho acuerdo, Genética Mandiyú autorizó a algunos actores - típicamente las cooperativas - a comprar semilla original, multiplicarla y venderla formalmente ${ }^{38}$, efectuando un pago por cada bolsa que obtuvieran en el proceso de multiplicación ${ }^{39}$, pero reteniendo la empresa el derecho de monitorear y controlar el proceso de multiplicación. Desde entonces la participación de Genética Mandiyú en el mercado de semillas creció del $8 \%$ en 2008 al $16 \%$ en 200940 .

Sin embargo, si bien está claro que los mercados informales empeoran el poder de negociación de los pequeños productores, porque limitan su acceso a la información y con ello su autonomía, también es

\footnotetext{
37 Nos referimos a la posibilidad de comprar a alguno de los varios multiplicadores autorizados de variedades del INTA. Con el tiempo, a medida que se difundían las semillas GM, el acceso a semillas convencionales en el mercado formal pasó a depender de la localización de los productores, de modo que los más próximos a los campos experimentales del INTA tenían mejor acceso. (Entrevista a agente del INTA).

${ }^{38} \mathrm{El}$ gobierno provincial financia a las cooperativas para comprar la semilla original.

${ }^{39}$ De acuerdo con información de Genética Mandiyú, el precio de una bolsa de semillas original del evento "apilado" se acercaba a los 200 dólares. El pago era de alrededor de 45 dólares por bolsa multiplicada e incluía el servicio de deslintado (proceso en que se limpia la semilla quitándole el linter o pelusa y haciendo más efectiva su siembra) de Genética Mandiyú.

${ }^{40}$ Entrevista con representante de la industria
}

evidente que no todo intento de formalización resulta beneficioso para ellos. Los propósitos de formalizar el mercado de semillas también podrían terminar perjudicando al pequeño productor si el precio para acceder a la tecnología aumentara demasiado, o si los intermediarios consiguieran consolidar su poder de negociación en la cadena al convertirse en intermediarios "autorizados".

En resumen, la introducción de semillas GM ha vuelto a los pequeños productores más vulnerables como compradores de insumos; tienen que adquirir una mayor variedad de ellos y solo pueden hacerlo en el mercado informal. Todavía no está claro de qué modo los recientes intentos por formalizar el mercado de semillas afectarán a los pequeños productores. Algunos riesgos podrían disminuir (los relacionados con el acceso a la información) y si mejorara la calidad de la semilla podrían mejorar también sus rendimientos. No obstante, los pequeños productores tendrán que afrontar costos más elevados y, dado que el número de intermediarios podría aminorar, su ya escaso poder de negociación en relación con los vendedores de insumos podría deteriorarse. La importancia de las asimetrías de poder en contra de los pequeños productores, dentro de la cadena de comercialización, queda ilustrada en el hecho de que uno de los principales reclamos de este sector es la definición de un precio mínimo que mejore por lo tanto su base de negociación ${ }^{41}$.

La situación de los grandes productores es claramente diferente y, como se ha estimado en la literatura, la adopción de la tecnología GM les ha aportado beneficios visibles. Por una parte, les permite ahorrar significativamente en costos laborales — por la mejora en el manejo de malezas - y también economizar en pesticidas, que ya no resultan necesarios por el uso de la semilla Bt (Qaim y de Janvry, 2005) — aunque la expansión del picudo relativiza esta afirmación. Por otra, la introducción del paquete asociado al GM ha permitido una ampliación de la frontera agrícola, convirtiendo a la soja en un cultivo apto para la región.

En suma, si la tecnología GM ha traído mejoras para los grandes productores en términos de rendimientos y rentabilidad, la brecha de rentabilidad entre ellos y los pequeños productores se ha ampliado, ya que estos últimos no han experimentado mejoras notables.

La mayor brecha de rentabilidad queda ilustrada en la presión ejercida sobre los pequeños productores

\footnotetext{
41 "Si hay un salario mínimo para el trabajador rural, ¿por qué no hay un precio mínimo para el productor?". Pequeño productor, Quitilipi. "El gobierno debe pelear para garantizar precios". Pequeño productor, Quitilipi.
} 
para que vendan sus tierras. Aunque no existen cifras oficiales acerca de la evolución de la concentración de las explotaciones (la información disponible más reciente proviene del censo agropecuario de 2002), ni tampoco sobre el éxodo de las áreas rurales (la información más reciente corresponde al censo de población de 2001) ${ }^{42}$, la percepción de que existe un fenómeno de esta naturaleza es generalizada, tanto entre los pequeños productores ${ }^{43}$ como entre los agentes del INTA y los representantes del gobierno ${ }^{44}$. Además, la cuestión de la venta de tierras y su concentración ha sido denunciada por diversas organizaciones de productores ${ }^{45}$ y mencionada en estudios académicos 46 .

Por último, es dable pensar que el aumento de la brecha de rentabilidad ha generado un consenso en torno

${ }^{42}$ Los últimos datos disponibles para el Chaco muestran que el número de explotaciones se ha reducido en un $21 \%$ entre 1988 y 2002. Por otra parte, mientras que la población rural en esa provincia representaba el 53\% en 1970, solo representaba el 17\% en 2001.

43 "No hay alternativa, si no hay tecnología en 10 años vamos a desaparecer, no vamos a existir. Hace 10 años éramos 32.000 habitantes: 17.000 en el campo y 15.000 en el pueblo. Hoy somos 42.000 habitantes y tenemos 31.000 en el pueblo y 11.000 en el campo [...] estamos existiendo: yo, por caprichoso, porque me gusta el algodón y defiendo al algodón". Pequeño productor y representante de cooperativa, Quitilipi.

44 "El algodón se decía que era un 'cultivo social' porque empleaba mucha mano de obra, ahora no es más asî'. Representante del gobierno, Pampa del Indio.

${ }^{45}$ Diferentes movimientos sociales expresaron su preocupación por esta situación. Por ejemplo, el Foro Multisectorial por la Tierra de Chaco (foroporlatierrachaco.blogspot.com/). Véase el artículo periodístico de Aranda, 2011.

${ }^{46} \mathrm{La}$ concentración de tierras en manos de grandes propietarios o corporaciones se destaca como un fenómeno notable desde la década de 1990 (véanse, por ejemplo, Rossi, 2006 y Manzanal, 2009). Véase también el trabajo de Valenzuela y Scavo (2009), en que se describen las resistencias de los pequeños productores en respuesta a la concentración que se produjo como consecuencia de la expansión del modelo de negocios en la producción agrícola en el Chaco. Otros autores, en cambio, afirman que la concentración, aunque notable, responde a un proceso global de intensificación de la producción en el marco del paradigma productivista (Trigo y Cap, 2006). de un discurso en que se proclama que el algodón no puede ser rentable para los pequeños productores. El gobierno provincial y algunos funcionarios del INTA, por ejemplo, sostienen que los pequeños productores deberían abandonar la producción de algodón y volcarse a cultivos alternativos (por lo general hortalizas), que son menos dependientes de escala, más acordes con las condiciones deterioradas del suelo, más relacionados con la soberanía alimentaria y potencialmente más rentables ${ }^{47}$.

Sin embargo, la mayoría de los pequeños productores no concuerdan con estas visiones. Como se mencionó antes, no solo tienen un vínculo cultural con el algodón, sino que les resulta difícil encontrar mercados para los productos alternativos, mientras que para el algodón al menos existe una cadena de comercialización que ya está organizada. Por lo tanto, las organizaciones de pequeños productores no suelen abogar por el abandono del cultivo, sino que sus principales reivindicaciones se relacionan con evitar las ventas de tierras y el éxodo rural y encontrar formas de incrementar su poder de negociación para que mejore la rentabilidad, entre ellas, el reclamo de un precio mínimo ${ }^{48}$.

\footnotetext{
47 "El algodón ya no es rentable para algunos productores con los que conversamos. Tenemos que ver a este grupo como productores de alimentos. Paradójicamente, la provincia del Chaco importa el $83 \%$ de la producción agrícola que consume y este sector [los pequeños productores], que es el más marginado y abandonado, es el que está en mejores condiciones para producir alimentos". Representante del gobierno, Pampa del Indio.

"Yo antes era un fanático del algodón, pero ahora dudo que sea útil para los pequeños productores, quizás existen alternativas más rentables como las verduras". Agente de una estación experimental del INTA, entrevistado en septiembre de 2010.

"Yo me quedo tranquilo con mi conciencia si creo alternativas productivas. Si yo voy y le digo a mi gente 'che, no hagan algodón' [...] pero nosotros estamos propiciando en algunos que no hagan algodón porque no les conviene! Porque no tienen suelo, porque no tienen acceso a la maquinaria. Al minifundista no le conviene". Agente de una estación experimental del INTA.

48 Entrevista con representantes de АPPCH (Asociación de Pequeños Productores del Chaco), Pampa del Indio.
} 


\section{IV}

\section{Conclusiones}

Durante la última década, los cultivos transgénicos se han expandido rápidamente. No obstante, sus beneficios no se distribuyen de manera homogénea entre los productores. En este trabajo se analizaron los cambios en rendimientos y rentabilidad generados por la adopción del algodón GM por parte de los pequeños productores de la provincia del Chaco.

A lo largo de este trabajo se sostuvo que los beneficios de la adopción de la tecnología dependen de una multiplicidad de aspectos, que exceden a las virtudes del artefacto tecnológico en sí mismo, en este caso, la semilla GM. Si la tecnología se concibe como una configuración socio-técnica, los beneficios esperados dependerán del contexto de adopción que deberá ser analizado desde distintos puntos de vista.

Sin embargo, en la literatura en que se describen las repercusiones del algodón GM en la Argentina no se han considerado los diferentes contextos en que las semillas GM han sido adoptadas. Las evaluaciones existentes tienden a homogeneizar las restricciones que enfrentan y los comportamientos de diferentes tipos de productores. Por lo tanto, también suelen generalizar las conclusiones para todos los tipos de productores.

En este trabajo se analizó la configuración sociotécnica de los pequeños algodoneros del Chaco, en particular, aquellas prácticas productivas que afectan a los rendimientos y la rentabilidad que obtienen en la producción de algodón, con el objetivo de identificar continuidades y rupturas vinculadas a la introducción de las semillas GM.

El principal argumento desarrollado en este trabajo es que las restricciones de los pequeños productores para mejorar sus rendimientos y rentabilidad en la producción de algodón continuaron o incluso se exacerbaron luego de la adopción de la tecnología GM. Dado que en la literatura se han identificado mejoras en la rentabilidad para el caso de los grandes productores como resultado de la adopción de esta tecnología, la brecha de rentabilidad entre grandes y pequeños productores tiene que haberse ampliado.

Una diferencia importante entre estos tipos de productores es que los pequeños adoptan una versión incompleta del paquete tecnológico. Como no tienen acceso al crédito formal para financiar el capital de trabajo y producen en una escala reducida, su producción no incluye todos los insumos del paquete y se sigue desarrollando manualmente.

Las prácticas deficientes de manejo de plagas tienen serias consecuencias desde que el picudo, que no es controlado por la tecnología GM, se convirtió en una amenaza real para la producción de algodón en la Argentina. Los pequeños productores son especialmente afectados por la plaga, ya que no suelen seguir las prácticas recomendadas al no contar con recursos para afrontar los costos que estas implican.

En resumen, las prácticas productivas de los pequeños productores no son las requeridas para obtener los mayores rindes de las semillas GM (porque no adoptan el paquete completo). Además, ha disminuido para ellos la asistencia técnica relacionada con la producción de algodón. En consecuencia, no es evidente que sus rendimientos hayan aumentado como resultado de la adopción de tecnología.

Además de los rendimientos, la rentabilidad también depende de la relación de precios entre insumos y producción. La evidencia cualitativa sugiere que los costos no han disminuido significativamente para este grupo, porque no contrataba mano de obra y no utilizaba pesticidas (al menos no sistemáticamente). Con respecto al precio del algodón, como su calidad no mejoró a consecuencia de la introducción de la nueva tecnología, no se puede concluir que los ingresos sean mayores por ese motivo.

De todas maneras, el precio real que afronta el pequeño productor depende, en gran medida, de su capacidad para negociar dentro de la cadena de producción. Como se ha visto, tradicionalmente los pequeños productores se han encontrado atrapados en esta cadena: por lo general pagan precios más altos por los insumos y reciben precios más bajos por la producción. Del presente análisis se desprende que la difusión del algodón GM ha debilitado la capacidad de negociación del pequeño productor: en primer lugar, porque depende de más insumos que antes, y en segundo lugar, porque la ampliación de los mercados informales disminuyó la disponibilidad de opciones y empeoró el acceso a información (por ejemplo, solo se venden semillas GM de identidad dudosa). Con su poder de negociación debilitado, se reducen sus posibilidades de mejorar la rentabilidad. 
Como la adopción de esta tecnología sí trajo claros aumentos de rentabilidad para los grandes productores (reportados en la literatura existente), se concluye que la brecha de rentabilidad entre ellos tiene que haberse ampliado.

Esta situación queda ilustrada por: i) los discursos que circulan entre los hacedores de política que sugieren que los pequeños productores deben abandonar la producción de algodón; ii) las conclusiones de varios investigadores acerca del aumento en la concentración de la tierra; iii) la percepción generalizada entre los productores del fenómeno del éxodo rural, y iv) las denuncias realizadas por organizaciones de campesinos sobre las presiones que reciben para vender sus tierras.

Ahora bien: ¿existen alternativas para intentar acortar esta brecha mediante una mejora en los rendimientos y la rentabilidad que obtienen los productores más pequeños?

Creemos que las tecnologías GM han sido ampliamente aceptadas porque no cuestionan el paradigma dominante en agricultura, basado en la intensificación de la producción y en la escala. En el marco de este paradigma "productivista" es probable que la brecha de rentabilidad se siga ampliando y la sostenibilidad de la producción de los pequeños productores de algodón siga en riesgo. Existen, sin embargo, paradigmas alternativos que han sido recientemente auspiciados por la literatura internacional. En particular, en el paradigma agroecológico se aboga por la preservación de los recursos naturales como el agua, el suelo y la biodiversidad (McIntyre y otros, 2008; Vanloqueren y Baret, 2009) y se propone una estrategia diferente de acumulación, basada en la autonomía en la provisión de insumos y un manejo sostenible de los recursos. En la Argentina existe una experiencia de producción de algodón agroecológico (Cooperativa Agroecológica del Litoral, ubicada en San Martín). No obstante, actualmente son pocos los productores involucrados. Para que un productor se reconvierta a la producción agroecológica se requiere un cambio radical en sus prácticas productivas y estar dispuesto a afrontar pérdidas económicas durante la transición. Estos inconvenientes podrían explicar por qué la agroecología no ha sido adoptada por los pequeños productores con la misma rapidez que la tecnología GM (que no pone en cuestión las prácticas a las que los productores están habituados).

Dentro del sistema de producción actual también es posible concebir algunas políticas que podrían contribuir a mejorar la situación de los productores más pequeños. De hecho, en el presente trabajo se han identificado algunas políticas y estrategias actualmente en curso que podrían mejorar su situación:

- El gobierno provincial del Chaco ha creado recientemente los "Consorcios de servicios rurales", que tienen el potencial de empoderar a las organizaciones de pequeños productores. Aunque muchos de ellos todavía no se encuentran en pleno funcionamiento y no han recibido los fondos provinciales prometidos, desde el momento en que esto suceda, se espera que sus socios puedan comercializar en forma conjunta, tanto para comprar insumos como para vender la producción. Ello aumentaría el poder de negociación en la cadena de comercialización, que es uno de los obstáculos más importantes para mejorar su rentabilidad.

- El Monotributo Social Agropecuario es una política nacional que crea un régimen fiscal especial para los pequeños productores, permitiéndoles estar legalmente inscritos de forma gratuita. Esta herramienta tiene la potencialidad de ampliar las alternativas para la venta de la cosecha, mejorando los precios que pueden obtener. Sin embargo, la cobertura de este sistema es aún muy baja. Deben implementarse acciones específicas destinadas a dinamizar el proceso administrativo y difundir la iniciativa para incrementar la cobertura y la confianza.

- El INTA desarrolló una cosechadora para surco estrecho que, por sus dimensiones, es adecuada para los pequeños agricultores. En la actualidad esta máquina no se encuentra disponible en el Chaco, aunque el INTA ya ha firmado acuerdos con empresas metalúrgicas a fin de producirla para el mercado nacional.

- El INTA promueve y contribuye a la organización de "ferias francas", donde los pequeños productores pueden vender sus productos para el consumo familiar (por ejemplo, jaleas, conservas y otros). La principal ventaja de estas iniciativas es que se eliminan los intermediarios y se promueve la diversificación de cultivos. Empero, por una parte la cantidad de feriantes que pueden participar en cada feria tiene un tope, lo que deja afuera a una gran cantidad de productores; por otra, en muchas localizaciones la feria tiene escasas posibilidades de generar una demanda adecuada, dado que la mayoría de su público está conformada por pequeños productores que se autoabastecen. Por consiguiente, se debería intentar insertar la producción en otros canales de comercialización, como los mercados centrales de las ciudades más grandes. 
- Desde el año 2009 existe un proyecto de investigación en el INTA, financiado por las provincias algodoneras, que está atacando el problema del picudo desde diversos frentes (desde la biotecnología hasta el mejoramiento convencional, pasando por los bioinsecticidas). Dado que la situación de los pequeños productores es bien conocida por el INTA, los resultados de estas investigaciones podrían redundar en beneficios concretos para la pequeña producción.

Aún queda mucho por hacer para mejorar la rentabilidad de los pequeños algodoneros del Chaco. A continuación se presentan algunos lineamientos de política que podrían llevarse a cabo sin un cambio radical del paradigma productivo:

- Mejorar la asistencia técnica destinada a los pequeños productores de algodón. Hay algunas técnicas de producción que pueden necesitar un cierto grado de adaptación a los requerimientos de los pequeños productores (por ejemplo, la siembra directa y en surco estrecho). El INTA dispone de experiencia de trabajo con estos grupos y tiene un importante papel que desempeñar en ese proceso.

- Crear esquemas financieros dirigidos a los pequeños productores. Estos esquemas deberían tener en cuenta los frágiles derechos de propiedad de este grupo, y ser diseñados para la adquisición de máquinas y el financiamiento de capital de trabajo. Podría ser sobre todo interesante que estos esquemas se organizaran en sintonía con el desarrollo de los consorcios y que permitieran créditos colectivos.

- Garantizar a los pequeños productores el acceso a semillas GM de buena calidad. Esto podría realizarse o bien eximiéndolos del pago de regalías o bien autorizando a los consorcios u otras organizaciones de productores para multiplicar semillas (es decir, ampliando el alcance del acuerdo existente).

- Controlar activamente la expansión del picudo del algodonero en las zonas aún no infestadas y asistir a los pequeños productores para que puedan controlar la plaga. Estas actividades deberían ser promovidas por el gobierno provincial y por el Servicio Nacional de Sanidad y Calidad Agroalimentaria (SENASA), que desde hace 10 años gestiona un programa de prevención y erradicación del picudo, en coordinación con los países vecinos afectados (el Brasil y el Paraguay).
Alemany, C. (2003), "Apuntes para la construcción de los períodos históricos de la extensión rural del INTA", La extensión rural en debate: Concepciones, retrospectivas, cambios y estrategias para el MERCOSUR, Buenos Aires, Instituto Nacional de Tecnología Agropecuaria (INTA).

Aranda, D. (2011), "La reforma agraria, al revés: De Menem a Kirchner, 15 años de soja”, $M U, N^{\circ} 43$, Buenos Aires, La Vaca.

Arza, V. y otros (2010), "Problemas de la regulación en semillas: El caso del algodón transgénico en el Chaco", Desarrollo económico, vol. 49, № 196, Buenos Aires, Instituto de Desarrollo Económico y Social (IDES).

Becerra, N., C. Baldatti y R. Pedace (1997), Un análisis sistémico de políticas tecnológicas. Estudio de caso: El agro pampeano argentino, 1943-1990, Buenos Aires, Centro de Estudios Avanzados, Universidad de Buenos Aires.

Bijker, W.E. (1995), Of Bicycles, Bakelites, and Bulbs: Toward a Theory of Sociotechnical Change, Cambridge, Massachusetts, MIT Press.

CCIA (Comité Consultivo Internacional del Algodón) (2009), "Biotech cotton and the technology fee", ICAC Recorder, vol. 27, N 1 .

Elena, M.G. (2010), "Costo de producción por hectárea de algodón", Instituto Nacional de Tecnología Agropecuaria (INTA) [en línea] http://inta.gob.ar/documentos/costo-de-produccion-por-hectareade-algodon-2009-10-para-surcos-estrechos-0-52m-1/

(2001), "Ventajas económicas del algodón transgénico en Argentina", Documento de trabajo, Estación Experimental Sáenz Peña, Instituto Nacional de Tecnología Agropecuaria (INTA).

Elena, G., S. Íbalo y E. Gesualdo (2006), "Evaluación económica de prácticas de manejo de algodón”, Chaco, EEA Saénz Peña.

Elena, G., R. Ybran y G. Lacelli (2008), "Evaluación económica de alternativas de sistemas de siembra y cosecha de algodón en las localidades de Santa Fe y Chaco", Instituto Nacional de Tecnología Agropecuaria (INTA).

Gárgano, Cecilia (2011), "La reorganización de las agendas de investigación y extensión del Instituto Nacional de Tecnología Agropecuaria (INTA) durante la última dictadura militar argentina (1976-1983)", Realidad económica, No 258, Buenos Aires, Instituto Argentino para el Desarrollo Económico (IADE).

Grossi-de-Sa, M.F. y otros (2007), "Susceptibility of Anthonomus grandis (cotton boll weevil) and Spodoptera frugiperda (fall armyworm) to a crylia-type toxin from a Brazilian Bacillus thuringiensis strain", Journal of Biochemistry and Molecular Biology, vol. 40, № 5 .

Klein, H.K. y D.L. Kleinman (2002), "The social construction of technology: structural considerations", Science, Technology \& Human Values, vol. 27, $\mathrm{N}^{\circ}$ 1, Sage Publications.

Kleinman, D.L. (1995), Politics on the Endless Frontier: Postwar Research Policy in the United States, Durham, Duke University Press.

Lanteri, A., V. Confalonieri y M.A. Scataglini (2003), "El picudo del algodonero en la Argentina: Principales resultados e implicancias de los estudios moleculares", Revista de la Sociedad Entomológica Argentina, vol. 62, № 3-4, Mendoza, Sociedad Entomológica Argentina.

Manzanal, M. (2009), "El desarrollo rural en Argentina. Una perspectiva crítica", Desenvolvimento rural no Cone Sul/ Desarrollo rural en el Cono Sur, J. Almeida y J.A. Dessimon Machado (orgs.), Porto Alegre, Associação Holos Meio Ambiente e Desenvolvimento.

McIntyre, B.D. y otros (eds.) (2008), International Assessment of Agricultural Knowledge, Science and Technology for Development (IAASTD): Global Report, Island Press. 
Pinch, T. (1996), "The social construction of technology: a review", Technological Change: Methods and Themes in the History of Technology, vol. 35, Harwood Academic Publishers.

Pinch, T. y W.E. Bijker (1987), "The social construction of facts and artifacts", The Social Construction of Technological Systems, W. Bijker, T. Hughes y T. Pinch (eds.), Cambridge, Massachusetts, Massachusetts Institute of Technology.

Qaim, M. y A. de Janvry (2005), "Bt cotton and pesticide use in Argentina: economic and environmental effects", Environment and Development Economics, vol. 10, N ${ }^{\circ}$ 02, Cambridge University Press.

(2003), "Genetically modified crops, corporate pricing strategies, and farmers' adoption: the case of Bt cotton in Argentina", American Journal of Agricultural Economics, vol. 85, $\mathrm{N}^{\circ}$ 4, Milwaukee, Agricultural \& Applied Economics Association.

Rosen, P. (1993), "The social construction of mountain bikes: technology and postmodernity in the cycle industry", Social Studies of Science, vol. 23, № 3, Sage Publications.
Rossi, D.O. (2006), "El contexto del proceso de adopción de cultivares transgénicos en la Argentina", Agromensajes, vol. 20, N 16-27, Rosario, Facultad de Ciencias Agrarias.

Trigo, E. y E. Cap (2006), "Diez años de cultivos genéticamente modificados en la agricultura argentina", ArgenBio, inédito.

Trigo, E. y otros (2002), Los transgénicos en la agricultura argentina: Una historia con final abierto, Buenos Aires, Libros del Zorzal.

Trigo, E., J. Falck-Zepeda y C. Falconi (2010), Biotecnología agropecuaria para el desarrollo en América Latina: Oportunidades y retos, Washington, D.C., Banco Interamericano de Desarrollo (BID).

Valenzuela, C. y A. Scavo (2009), La trama territorial del algodón en el Chaco: Un enfoque multiescalar de espacios en transición, Buenos Aires, Editorial La Colmena.

Vanloqueren, G. y P.V. Baret (2009), "How agricultural research systems shape a technological regime that develops genetic engineering but locks out agroecological innovations", Research Policy, vol. 38, $\mathrm{N}^{\circ}$ 6, Amsterdam, Elsevier.

Williams, R. y D. Edge (1996), "The social shaping of technology", Research Policy, vol. 25, $\mathrm{N}^{\circ}$ 6, Amsterdam, Elsevier. 